\title{
Integrating International Students: The Missing Link in Portuguese Higher Education Institutions
}

\author{
Cristina Sin* and Orlanda Tavares \\ Agency for Assessment and Accreditation of Higher Education (A3ES) and Centre for Research in Higher Education \\ Policies (CIPES), Portugal \\ *Corresponding author: Email: csin@ cipes.up.pt \\ Address: Rua $1^{\circ}$ Dezembro 399 4450-227 Matosinhos Portugal
}

\section{Introduction}

Over the past few years, Portugal has become a proactive recruiter of international students (Sin, Antonowicz and Wiers-Jenssen 2019). Portuguese institutions have been the preferred choice of students from the former Portuguese colonies coming through agreements with the Portuguese government (França, Alves, and Padilla 2018). Consequently, in 2017-18 around two-thirds of international students came from Portuguese-speaking countries, such as Brazil, Angola, Cape Verde, Mozambique, São Tomé and Príncipe, Guinea Bissau and East Timor (DGEEC 2018).

Although proactive recruitment of full-degree international students was far from a common practice among public institutions, after 2014 this has become a priority (Nada and Araújo 2018a; Sin, Tavares and Cardoso 2019). Various factors have encouraged this shift in attitude: declining enrollments and highly pessimistic demographic projections (Dias et al. 2013); the prioritization of incoming student mobility in the internationalization strategy of Portuguese higher education (MADR/MEC 2014); and the recent Statute of the International Student, a piece of legislation from 2014 which allows public institutions to charge higher fees for international students.

Despite the growth of international student migration and the active recruitment of international students by host countries, there are only a handful of studies that investigated institutional strategies for integrating international students, or their experiences, in the host country (see for example Mosneaga and Agergaard 2012; Urbanovič, Wilkins, and Huisman 2014; Nada and Araújo 2018a; O'Connor 2018;). Also in Portugal, research on this topic is rather scarce, and existing studies mainly focused on students' perceptions (Campos and Lima 2012; Alves 2013; Nada and Araújo 2018a, 2018b). This paper, while also reporting on student experiences, adds the institutional perspective of top and middle managers. It aims to investigate institutional strategies for the integration of international students and student experiences in this regard. The research questions to answer are: What strategies do institutions employ to integrate international students, if any, and are these effective? Do international students feel integrated socially and academically in the institution? What are the reasons for their perceptions? This will allow inferring opportunities and challenges of integration policies and experiences, and formulating some possible ways forward to improve international students' experience.

\section{Integrating international students}

A main challenge that higher education institutions must address to ensure their global attractiveness is international students' well-being and satisfaction during their studies. A successful integration of these students is therefore paramount to achieve the goal of increasing the internationalization of the student body. Integration thereby refers to the set of institutional activities meant to cater for international students, not only in the early stages following their arrival, but also throughout their stay. This is, however, not an easy task because international students face 
multiple difficulties, not only related to a new social and academic environment, but also to the necessary cultural adjustment (Brown and Holloway 2008; Zhou et al. 2008). Furthermore, international students are also reported to be more likely to experience homesickness and discrimination (Poyrazli and Lopez 2007; Brown and Holloway 2008; Thurber and Walton 2012; Nada and Araújo 2018a). According to Poyrazli and Lopez (2007), higher levels of perceived discrimination can lead to lower self-esteem, higher identification with other international students, and poor adjustment to the new environment.

Institutions can play a crucial role in counteracting the negative effects of culture shock, homesickness and discrimination, and in assisting students to navigate the acculturation process. Ward (2015) recommends four key areas for institutional action: welcoming international students, adjusting services and programs to meet their needs, facilitating integration between international and other students, and assessing students' experiences. The importance of pre-arrival information about, for example, the culture, the school, the academic program, and links to a range of university services is highlighted by several studies (Brown and Holloway 2008; Thurber and Walton 2012; PerezEncinas and Ammigan 2016). The benefits of interventions meant to help students interact with the host culture are also mentioned by various authors. For example, pairing international and host-country students has been found to increase sociocultural and psychological adaptation and to reduce acculturative stress (Thompson and Esses 2016); regular social gatherings can give students a sense of belonging (Brown and Holloway 2008); and forming support groups for students can help to raise awareness among home students about how certain behavior could be perceived as discriminatory (Poyrazli and Lopez 2007). Such measures could help to reduce the culture shock (Zhou et al. 2008) experienced by international students.

Support services and infrastructures oriented to cater for international students are considered an essential element to ensure that these students' needs, different from the needs of national students, are considered (Mosneaga and Agergaard 2012; Perez-Encinas and Ammigan 2016). An international unit could provide comprehensive services ranging from pre-arrival information to providing advice on practical matters, such as residence permits, visas, accommodation, health care, etc. Additionally, other support services may be necessary to ensure students get integrated academically, culturally and socially, such as with counseling (Brown and Holloway 2008) or academic support (Brown and Holloway 2008; Gu, Schweisfurth, and Day 2010). Indeed, students are confronted with a new pedagogic environment which makes them feel uncomfortable and unsure about their academic skills: They worry about failing the exams, about not being able to answer questions in class, or they feel embarrassed about speaking up in class. Since students are generally unaware of these challenges before they arrive, it is important that institutions anticipate them and provide early academic support and integration. Moreover, establishing relationships with teachers is a major challenge ( $\mathrm{Gu}$, Schweisfurth, and Day 2010). Assigning teacher-tutors for international students and/or intervention programs to raise awareness of the difficulties experienced by international students among academic and administrative staff are potential measures to improve international students' academic integration (Brown and Holloway 2008; Gonçalves 2009).

Finally, language is also highlighted as a challenge both for academic and social integration (Poyrazli and Lopez 2007; Thurber and Walton 2012; Van Mol and Michielsen 2015; Thompson and Esses 2016). In Portugal, at first sight this would not be an issue for the majority of international students, as they mainly come from Portuguese-speaking countries. However, they speak the language differently, filtered through their own culture. Several authors who focused on the Portuguese context (Franca et al. 2018; Nada and Araújo 2018b) have already shown that students who come from Lusophone countries can also experience problems understanding the Portuguese language spoken in Portugal. If the academic community is unaware of these cultural and linguistic differences, they tend to treat them the same as they treat domestic students. For this reason, Gonçalves (2009) calls them 'invisible.' 


\section{Methodology}

This small-scale qualitative study was conducted in 2017-2018 through eight semi-structured interviews at two public universities in the northern area of Portugal (four in each) with institutional representatives in positions of management and decision-making related to international students. In public universities international student recruitment is a recent priority, contrary to private institutions which have always been interested in attracting these students, as sources of valuable revenue (See Table 1).

Table 1. Interviewed institutional representatives and focus groups with international students

\begin{tabular}{|l|l|l|}
\hline & Institutional representatives & Students \\
\hline Institution A & Vice-rector for Internationalization & Focus Group A \\
& Vice-rector for Academic Affairs & \\
& Head of International Office & \\
& Head of Academic Affairs & \\
\hline Institution B & $\begin{array}{l}\text { Internationalization Adviser to Rector } \\
\text { Head of International Office } \\
\text { Head of Academic Affairs } \\
\text { Head of Communication, Image and Public Relations Unit }\end{array}$ & \\
\hline
\end{tabular}

Additionally, two focus groups with international students were conducted at each university to determine if strategies are effective judging by the students' experiences. The international students were enrolled in first degrees, except one student enrolled in a master degree program. The discussions were held in Portuguese as all participants were from Portuguese-speaking countries, reflecting the majority of international student enrolments. The interviews and focus groups lasted around an hour. They were transcribed and analysed with the help of the qualitative analysis software MaxQDA, following a grounded theory method adapted from Strauss and Corbin (1990). Grounded theory consists of the pursuit of emergent themes through early data analysis and coding, construction of abstract categories that synthesise the phenomenon in question, further refinement of categories by means of additional data collection and the integration of categories in an overarching theory. It is therefore the emergence of theory from data that gives grounded theory its particular characteristics. The following two sections address the perspectives of institutional representatives and of students.

\section{Perceptions of institutional representatives}

The interviews show that neither university has a clearly articulated strategy for the integration of international students, although both have become more proactive recruiters following the Statute of the International Student and the financial incentives implied therein. The institutions are in a process of finding their feet and looking for the best way to organize themselves to respond to an increasingly international student body. Institutional representatives mention some measures that have been taken to integrate international students, including reception activities, logistical support on arrival (accommodation, opening bank account, visas, etc.), mentorship programs, staff training, and social activities. However, these measures seem to be developed ad hoc and at an incipient stage:

We still have no concrete measures to receive international students. We have a 'reception machine' for exchange students, which in my opinion works very well, [...] but we have not taken advantage of the whole structure and reception methods to integrate international students who come here for a full degree. This is merely a question of 
internal organisation. [...] We are still not well organised, the databases are not accessible to the interested parties and those people who could help integrate students are still not fully informed. We are struggling to support students before they come, to be with them in the critical moment of arrival and to accompany them in the first two weeks. (Head of International Office, Institution B)

Indeed, institutional representatives generally acknowledge the integration of international students as a challenge rather than a reality. A structure with exclusive remit and competence to support international students in their interaction with the institution seems to be a missing key element. As an interviewee stated:

A difficulty within the university is having a formal structure, because we have not yet managed to organise ourselves internally to say that we have such competences in this structure and that the people who work there have a broad knowledge which spans from application to registration, from the point of view of what we tell them and how we communicate with them. (Head of Academic Affairs, Institution B)

Currently, these students fall under the remit of academic services, which focus on national students and lack expertise to answer the needs of international students. In contrast, international units, which have experience of working with Erasmus students, are only now starting to be called upon, but have limited resources to do so. In fact, financial resources are explicitly identified as a challenge, similar to other small countries (Urbanovič, Wilkins, and Huisman 2014). According to an interviewee:

There is the funding issue. We have Erasmus funding to support Erasmus students' integration. There is no European funding to support the integration of non-Erasmus students [...] Tuition fees go fully to the faculties. Therefore, it is the faculties that manage all issues associated with the stay of these students in the schools, in the departments. (Head of International Office, Institution A)

Changing staff mentality and equipping them with competences to deal with cultural diversity is another challenge identified by the interviewees. This suggests that the institutionalization and professionalization of support services for international students is critical to move beyond this embryonic stage of development (see Mosneaga and Agergaard 2012; Perez-Encinas and Ammigan 2016).

\section{Students' perceptions}

Students' predominantly negative opinions regarding their integration, expressed during the focus group discussions, reinforce the need for articulated institutional action and support. Negative perceptions are much more frequent after arrival than before arrival, suggesting that the main difficulties arise during their integration/adaptation. Indeed, social and academic integration stood out, by far, as the main difficulties experienced by international students. In terms of social integration, they struggle to get close to their Portuguese colleagues, to connect, and establish friendships. For this reason, they tend to get together with other international students or with friends from the same home country. They often experience feelings of loneliness and tend to isolate themselves, mirroring findings from other countries (Brown and Holloway 2008; Poyrazli and Lopez 2007). Academic integration is also highlighted as a major negative experience in several aspects. First, differences between the home and host country higher education systems and/or pedagogies are mentioned, and students generally do not feel guided or supported either by their teachers, or by the institution regarding various aspects of the academic life: 
Sometimes, for us from abroad...there we have a different kind of teaching: teachers come, they speak and we write everything they say. Here teachers speak, speak, speak, put the slides and we take notes of what we think is important. There it was not like this, even at university. It was not technology-based like here, it was more like us making photocopies, studying those, doing exams, and so on. Here it is more complicated. (Focus group B)

Second, students feel excluded academically by their peers, who leave them aside when they have to conduct group-work. According to a student from an African country:

No one comes and says: 'I want to work with you'. They always want to work among themselves. Many times, I would be left without a group and then they would sort one out to integrate me. [...)]The task involved knowing the Portuguese reality, do field work and we struggled with it because we had no idea. [...] In the group I joined there was little interest, I even tried, but then I ended up not questioning anything and gave up. (Focus group B)

Another negative experience reported by the international students, although in a lesser degree, is related to language, which represents an obstacle aggravating both social and academic integration. Despite coming from countries where Portuguese is an official language, they struggle to follow the language spoken in Portugal because of differences in accent, pronunciation, pace, and semantics. As such, our findings are in line with those reported by Franca et al. (2018) and Nada and Araújo (2018b). However, this seems to go unnoticed, which confirms the designation 'invisible students' (Gonçalves 2009). As a student from Brazil reported, this not only led to social exclusion, but also affected her academic performance:

I could not understand anything that was being taught. I could not follow the Portuguese from Portugal. [...]My grades in Brazil were one thing, here they were another. Here I was always the worst student in class. Besides not understanding and feeling lonely, when I had doubts I was embarrassed to ask. Because I did not feel welcomed, as if they were doing me a favour. (Focus group A)

With less emphasis, and in one university only, negative experiences emerged related to logistical and practical issues, such as accommodation, opening bank accounts, or visas. For example, a Brazilian student lamented the fact that the cheaper university student accommodation was not available for international students:

I heard about an accommodation and scholarships service. I sent them an email. They said I was not Portuguese, and that the Portuguese students had priority. I had to have an equal rights statute. This statute is only granted six months after living here and it would allow me to apply for a place in halls of residence. (Focus Group A)

In the other university, these issues were not critical because the focus group participants generally came through partnerships or agreements involving the host university and organizations in their home country. As a consequence, such practical issues were largely taken care of by the organizations, as the following excerpt illustrate:

The university helped me, they dealt with everything for us, I mean, the students from Timor, in terms of accommodation, residence permit, fiscal number, everything. (Focus group B) 


\section{Conclusions and Practical Implications}

Strategies employed by the Portuguese institutions to integrate international students are still scarce, developed ad hoc, and misarticulated according to institutional representatives. Uncoordinated measures apparently fail to ensure a positive experience for international students, judging by their opinions, regarding both social and academic integration. A first implication arising from this study is the need for a strategy capable of providing coordination, direction, and focus to activities meant to support international students. The implementation of this strategy could be the responsibility of a dedicated international office exclusively focused on international students, equipped with staff with intercultural competences. This appears particularly relevant for higher education systems and/or institutions for which the internationalization of the student body is a recent priority.

Language unexpectedly emerges as an issue for students from Portuguese-speaking countries, a group that tends to be 'invisible' given the shared language and the assumption of their familiarity with Portugal. Institutions, when designing strategies meant to improve the experience of international students, need to bear in mind that most come from Portuguese-speaking countries and therefore discriminate between the needs of different groups of students, avoiding a one-size-fits-all approach. Whether or not the problems encountered by Portuguese-speaking students are aggravated by the historical specificities of the Portuguese colonial past (see for example França, Alves, and Padilla 2018) is a moot point.

In order to prevent social and academic exclusion triggered by linguistic and cultural differences, the following institutional measures could be considered: pre-arrival information to manage student expectations about the country which is assumed they know, including assistance with accommodation; pairing international with national students to foster mutual knowledge and inter-cultural understanding; assigning teacher-tutors to develop the learning skills needed in a different pedagogic environment; and raising awareness among staff of the importance of promoting a more inclusive and multicultural environment. Such measures could turn institutions more responsive to cultural diversity rather than assuming a paternalistic attitude towards the supposed deficits of international students (Nada and Araújo 2018b). Moreover, any measure taken to integrate international students must be properly thought through and monitored so as not to single them out, because this could lead to unintended opposite effects of isolation and segregation (Fincher and Shaw 2009; Nada and Araújo 2018b).

\section{References}

Alves, Elisa da Palma. 2013. "Estudantes internacionais no ensino superior português: motivações, expectativas, acolhimento e desempenho. O caso dos estudantes angolanos, brasileiros e cabo-verdianos no ISCTE-IUL." Master Dissertation. Retrieved from www: http://hdl.handle.net/10071/7369

Brown, Lorraine, and Immy Holloway. 2008. "The initial stage of the international sojourn: excitement or culture shock?" British Journal of Guidance \& Counselling 36(1): 33-49.

Campos, G. A. G., and Manolita Correia Lima. 2012. "Mobilidade académica internacional e a transformação das práticas pedagógicas na direção da transculturalidade, a experiência de estudantes originários dos países de língua portuguesa." Revista: Ensino Superior: 35-45.

Dias, Rui, Maria Filomena Mendes, Maria Graça Magalhães and Paulo Infante. 2013. "The role of population projections for a redefinition of the Portuguese higher educational institutional network," in Joint Eurostat UNECE-ISTAT Work Session in Demographic Projections, Rome, Italy, October 2013.

DGEEC - Direção-Geral de Estatísticas da Educação e Ciência. 2018. Principais resultados do RAIDES 17 Mobilidade Internacional Inscritos 2017/18. Lisboa: DGEEC. 
Fincher, Ruth and Kate Shaw. 2009. "The unintended segregation of transnational students in central Melbourne." Environment and Planning A, 41(8): 1884-1902.

França, Thais, Elisa Alves, and Beatriz Padilla. 2018. "Portuguese policies fostering international student mobility: a colonial legacy or a new strategy?" Globalisation, Societies and Education: 1-14.

Gonçalves, Susana. 2009. "Internacionalização em casa: a experiência da ESEC.” Exedra: Revista Científica (1): 139166.

Gu, Qing, Michele Schweisfurth, and Christopher Day. 2010. “Learning and growing in a 'foreign' context: Intercultural experiences of international students." Compare 40(1): 7-23.

MADR/MEC. 2014. Uma estratégia para a internacionalização do ensino superior português [A strategy for the internationalisation of Portuguese Higher Education]. Lisbon: Ministry of Regional Development and Ministry of Education.

Mosneaga, Ana, and Jytte Agergaard. 2012. "Agents of internationalisation? Danish universities' practices for attracting international students." Globalisation, Societies and Education 10(4): 519-538.

Nada, Cosmin I., and Helena C. Araújo. 2018a. 'When you welcome students without borders, you need a mentality without borders' internationalisation of higher education: evidence from Portugal. Studies in Higher Education: 114. https://doi.org/10.1080/03075079.2018.1458219

Nada, Cosmin I., and Helena C. Araújo. 2018b. "Migration and education: A narrative approach to the experience of foreign students in Portugal.” London Review of Education, 16(2): 308-324.

O’Connor, Sinéad. 2018. "Problematising strategic internationalisation: tensions and conflicts between international student recruitment and integration policy in Ireland." Globalisation, Societies and Education 16(3): 339-352.

Perez-Encinas, Adriana, and Ravichandran Ammigan. 2016. "Support services at Spanish and US institutions: A driver for international student satisfaction." Journal of International Students 6(4): 984-998.

Poyrazli, Senel, and Marcos Damian Lopez. 2007. "An exploratory study of perceived discrimination and homesickness: A comparison of international students and American students." The Journal of Psychology 141(3): 263-280.

Sin, Cristina, Dominik Antonowicz, and Jannecke Wiers-Jenssen. 2019. "Attracting International Students to SemiPeripheral Countries: A Comparative Study of Norway, Poland and Portugal." Higher Education Policy: 1-24.

Sin, Cristina, Orlanda Tavares, and Sónia Cardoso. 2019. "Portuguese Institutions' Strategies and Challenges to Attract International Students: External Makeover or Internal Transformation?” Journal of International Students 9(4): 1095-1114.

Strauss, Anselm, and Juliet Corbin. 1990. Basics of Qualitative Research: Grounded Theory Procedures and Techniques. Thousand Oaks, CA: Sage publications.

Thomson, Clint, and Victoria M. Esses. 2016. "Helping the transition: Mentorship to support international students in Canada." Journal of International Students 6(4): 873-886.Thurber, Christopher A., and Edward A. Walton. 2012. "Homesickness and adjustment in university students." Journal of American college health 60(5): 415-419.

Urbanovič, Jolanta, Stephen Wilkins, and Jeroen Huisman. 2016. "Issues and challenges for small countries in attracting and hosting international students: the case of Lithuania." Studies in Higher Education 41(3): 491-507.

Van Mol, Christof, and Joris Michielsen. 2015. "The reconstruction of a social network abroad. An analysis of the interaction patterns of Erasmus students." Mobilities 10(3): 423-444.

Ward, H.H. 2015. Internationalization in Action. Washington, DC: American Council on Education. Retrieved from http://www.acenet.edu/news-room/Documents/Intlz-In-Action-Intlz-Co-Curriculum-Part-1.pdf

Zhou, Yuefang, Divya Jindal-Snape, Keith Topping, and John Todman. 2008. "Theoretical models of culture shock and adaptation in international students in higher education." Studies in Higher Education 33(1): 63-75. 